\title{
Distribution and Concentration of Cholesteryl Ester Transfer Protein in Plasma of Normolipemic Subjects
}

\author{
Yves L. Marcel," Ruth McPherson," Mireille Hogue," Helena Czarnecka," Zbigniew Zawadzki, \\ Philip K. Weech," Mary E. Whitlock, \\ ${ }^{*}$ Laboratory of Lipoprotein Metabolism, Clinical Research Institute of Montreal, Montreal, Quebec, H2W $1 R 7$ Canada; ${ }^{\ddagger}$ Lipid \\ Research Unit, Royal Victoria Hospital, McGill University, Montreal, Quebec, H3A 1A1 Canada; and ${ }^{\S}$ Department of Medicine, \\ Columbia University College of Physicians and Surgeons, New York, New York 10032
}

\begin{abstract}
A MAb (TP-2) directed against human cholesteryl ester transfer protein (CETP) has been applied to the development of a competitive solid-phase RIA. Experiments with immobilized CETP have shown that upon incubation with plasma or HDL in the presence of Tween $(0.05 \%)$ apo A-I (but not apo A-II) binds to CETP while TP-2 binding to CETP is concomitantly decreased. With high detergent concentration $(0.5 \%$ Triton), the interference is eliminated and a specific RIA in which all plasma CETP fractions have the same affinity can be obtained. Plasma levels of CETP, apo A-I, lipids, and lipoproteins were measured in 50 normolipemic, healthy subjects of both sexes. CETP levels varied nearly fourfold with a mean value of $1.7 \mu \mathrm{g} / \mathrm{ml}$. CETP was positively correlated only with apo A-I $(r=0.38)$ and HDL-triglyceride $(r=0.39)$. In 29 other normolipemic subjects, where several apolipoproteins were also measured, significant correlations of CETP with apo A-I (0.41), apo E (0.43), and HDL-cholesterol (0.41) were observed, but there was no significant relationship between CETP and either apo A-II, B, or D. In other experiments CETP was shown to be present mostly in $\mathrm{HDL}_{3}$ and VHDL, to display exclusively an $\alpha_{2}$-electrophoretic migration, and to occur within discrete particles ranging in size from 129 to 154 $k D$. In conclusion, the association of CETP with apo A-I-containing lipoproteins probably explains the correlation between CETP and apo A-I levels. The relationship between CETP and apo $E$ suggests either a common metabolism or a specific cooperative role in cholesterol ester transport for these proteins. ( $J$. Clin. Invest. 1990. 85:10-17.) cholesterol • cholesteryl ester transfer protein • high-density lipoprotein • lipoprotein
\end{abstract}

\section{Introduction}

Plasma lipoproteins are continuously modified during intravascular metabolism by the exchange and transfer of lipids and

A portion of this paper was presented at the American Heart Association 1988 Scientific Session.

Address reprint requests to Dr. Yves L. Marcel, Laboratory of Lipoprotein Metabolism, Clinical Research Institute, 110 Pine Avenue West, Montreal, Quebec, H2W 1 R7 Canada.

Received for publication 12 January 1989 and in revised form 25 August 1989.

1. Abbreviations used in this paper: CETP, cholesteryl ester transfer protein; CM, carboxy-methyl; LCAT, lecithin:cholesterol acyltransferase.

J. Clin. Invest.

(C) The American Society for Clinical Investigation, Inc.

0021-9738/90/01/0010/08 \$2.00

Volume 85, January 1990, 10-17 apolipoproteins (1). Transfer of cholesteryl esters, triglycerides, and phospholipids is facilitated by a specific protein identified as cholesteryl ester transfer protein (CETP). ${ }^{1}$ Purified human CETP (2) was used recently to obtain MAbs that were shown to inhibit or remove from plasma all transfer activities for cholesteryl esters and triglycerides and some of the phospholipid transfer activity (3). The remaining activity was mediated by a distinct protein, identified as phospholipid transfer protein, that does not transfer neutral lipids (4).

CETP is responsible for the net mass transfer of the cholesteryl esters formed by lecithin:cholesterol acyltransferase (LCAT) within HDL to the triglyceride-rich lipoproteins, chylomicrons, and VLDL (5). Since the latter are simultaneously transformed by lipolytic enzymes into remnants and intermediate density lipoproteins, which are subsequently removed by the hepatic receptors or further processed into $\operatorname{LDL}(6,7)$, it is clear that CETP directly mediates an important alternate pathway in the intravascular transport of cholesteryl esters.

The MAbs against CETP have allowed the development of an RIA for the determination of CETP levels as reported in a preliminary communication (8). A modified version of this assay reported here has been applied to measure plasma CETP levels in normolipemic subjects and to relate them to the lipid and lipoprotein parameters that define normal healthy subjects. We also define here the distribution of CETP in plasma lipoprotein subfractions separated by density, size, and charge.

\section{Methods}

Blood samples. Blood was obtained from normolipemic healthy volunteers recruited from the personnel of the Clinical Research Institute of Montreal and Toronto's St. Michael's Hospital after a 12-h fast unless otherwise indicated. The study was approved by the local institutional review boards. None of the subjects were taking any lipid-active medication. EDTA plasma was collected under standard conditions and a serine protease inhibitor (diethyl paranitrophenyl phosphate, E600, 2 $\mathrm{mM}$ ) was added to all samples. Lipoproteins were separated either by sequential isopycnic ultracentrifugation (9) or by discontinuous gradient ultracentrifugation (10). Plasma samples were stored at $4^{\circ} \mathrm{C}$ and analyzed for CETP within $1 \mathrm{wk}$ or stored at $-80^{\circ} \mathrm{C}$.

Tween-based RIA for CETP. Antibody 5C7, now called TP-2 (3), was selected on the basis of its high immunoreactivity with native plasma CETP for the development of a solid-phase competitive RIA. The primary antigen represented by the partially purified CETP obtained after carboxy-methyl (CM)-cellulose chromatography (2) was diluted to $6 \mu \mathrm{g}$ protein/ml with $15 \mathrm{mM} \mathrm{Na}_{2} \mathrm{CO}_{3}, 35 \mathrm{mM} \mathrm{NaHCO}$, $0.02 \% \mathrm{NaN}_{3}, \mathrm{pH} 9.6$, and added $(200 \mu \mathrm{l})$ to plastic wells (Removawells; Dynatech Laboratories, Inc., Alexandria, VA). The wells were kept in a moist chamber at $20^{\circ} \mathrm{C}$ for $18 \mathrm{~h}$, then washed once with PBS and saturated with $300 \mu \mathrm{l}$ PBS with $1 \% \mathrm{BSA}, 0.02 \% \mathrm{NaN}_{3}$, and $1 \mathrm{mM}$ EDTA at pH 7.2 for $60 \mathrm{~min}$. The wells were washed once with PBS and refilled with $200 \mu \mathrm{l}$ of a mixture of equal volumes of MAb TP-2 and antigen, both diluted with the reaction buffer (PBS with 1\% BSA, $0.02 \% \mathrm{NaN}_{3}$, and $0.05 \%$ Tween-20). After $90 \mathrm{~min}$ at $20^{\circ} \mathrm{C}$ the wells were washed three times with reaction buffer, blotted dry, and incu- 
bated another $90 \mathrm{~min}$ at $20^{\circ} \mathrm{C}$ with $200 \mu \mathrm{l}$ of ${ }^{125}$ I-anti-mouse IgG (2 $\times 10^{5} \mathrm{cpm} /$ well representing $22 \mathrm{ng}$ of labeled antibody) prepared as described earlier (11). The wells were washed three times with reaction buffer, blotted dry, and counted in a gamma counter.

Triton-based RIA for CETP. The coating and saturation steps were identical to those in the Tween assay. The dilutions of competing antigen were prepared in PBS with $1 \%$ BSA, $0.02 \% \mathrm{NaN}_{3}, 1 \mathrm{mM}$ EDTA at pH 7.2, and Triton X-100 (1\% final concentration) and incubated at $37^{\circ} \mathrm{C}$ for $90 \mathrm{~min}$ or at $20^{\circ} \mathrm{C}$ for $18 \mathrm{~h}$ with the same results. Equal volumes $(100 \mu \mathrm{l})$ of the diluted and incubated antigen and ${ }^{125}$ I-labeled TP-2 $(100,000 \mathrm{cpm}, 9 \mathrm{nCi} / \mathrm{ng} \mathrm{IgG}$ protein in PBS with $1 \%$ BSA, $0.02 \% \mathrm{NaN}_{3}$, and $1 \mathrm{mM}$ EDTA at pH 7.2) were mixed and added to the wells. The competitive immunoreaction was carried out at $20^{\circ} \mathrm{C}$ for $90 \mathrm{~min}$ with a final concentration of $0.5 \%$ Triton. The wells were then washed three times with PBS, blotted dry, and counted.

The appropriate dilution of TP-2 was determined by antibody titration and the concentration used in the assay (diluted 1:150,000) provided $\sim 50 \%$ of maximum binding with plasma diluted $\sim 1: 32$ or 1:64. The intra- and interassay coefficients of variation at $\sim 1.6 \mu \mathrm{g}$ CETP/ml were 6.3 and $8.2 \%$, respectively. The lower limit of detection of the assay was $\sim 20 \mathrm{ng}$ CETP $/ \mathrm{ml}$. A secondary standard serum pool was prepared from four normolipemic donors, diluted fourfold with PBS containing $1 \mathrm{mM}$ EDTA, $1 \mathrm{mM}$ PMSF, $1 \mathrm{mM}$ E600, and $0.02 \%$ $\mathrm{NaN}_{3}$, and kept at $-80^{\circ} \mathrm{C}$. This standard pool was calibrated with pure CETP (based on electrophoretic criteria of charge and $M_{\mathrm{r}}$ ) obtained by triglyceride-emulsion binding and gel filtration (2) and treated with either $0.1 \mathrm{SDS}$ or $0.5 \%$ Triton for $30 \mathrm{~min}$ at $37^{\circ} \mathrm{C}$ (with similar results) before dilution for RIA. The mass of CETP in the primary standard was determined by amino acid analysis after delipidation with hexane. Norleucine was added as an internal standard before the delipidation step.

Immunoblotting of agarose gel and polyacrylamide gradient gel electrophoresis. Plasma lipoproteins were electrophoresed on agarose gels (Paragon Lipo Gels; Beckman Instruments, Inc., Palo Alto, CA) according to the instructions of the manufacturer. After electrophoresis the lipoproteins were transferred to nitrocellulose paper $(0.45 \mu \mathrm{m}$; Schleicher \& Schuell, Inc., Keene, NH) by providing contact between the gel and a sheet of wet nitrocellulose paper. As judged by Sudan black staining of the gels, the transfer was completed in $5 \mathrm{~min}$. The nitrocellulose paper was saturated with $3 \%$ polyvinylpyrrolidone ( 44,000 mol wt; BDH Inc., Montreal, Que.) in Tris-buffered saline $\left(1 \mathrm{~h}, 37^{\circ} \mathrm{C}\right)$ and further processed as described previously (12). Autoradiography was performed on XAR-5 film (Eastman Kodak Co., Rochester, NY) with an intensifier screen (Cronex; DuPont Instruments, Wilmington, DE). Nondenaturing electrophoresis of plasma was performed on polyacrylamide gradient gels (4-30\%; Pharmacia, Uppsala, Sweden) in $14 \mathrm{mM}$ Tris, $110 \mathrm{mM}$ glycine, $0.01 \% \mathrm{NaN}_{3}, \mathrm{pH} 8.3$, as described earlier (13), and after electrophoretic transfer on nitrocellulose paper the immunoblots were carried as described (12).

Analyses. Plasma cholesterol and triglyceride, HDL-cholesterol and triglyceride, and LDL-cholesterol were determined by the methods of the Lipid Research Clinic protocol (14) at the Core Lipid Laboratory, St. Michael's Hospital, with the assistance of Dr. Philip Connelly. All RIA for immunoassays of apolipoproteins have been described previously, including apo A-I (15), B (11), D (16), and E (17). The RIA for apo A-II was carried out using a MAb that was a generous gift from Dr. Linda Curtiss (Scripps Institute, La Jolla, CA).

Statistical methods. Partial correlation analyses (Pearson correlation coefficients) and stepwise multiple regression analyses were performed using the SAS statistical package (18).

\section{Results}

Based on the capacity of this MAb to inhibit and remove all CETP activity from human plasma and on the strength of the signal obtained, MAb TP-2 was chosen for the development of a competitive solid-phase RIA for plasma CETP. In the pres- ence of Tween and as described under Methods, complete displacement of the antibody could be obtained with either serum, plasma, or purified CETP preparations.

When this assay was first applied to the determination of CETP levels in a large group of normolipemic subjects (8), CETP was found to be significantly correlated with apo A-I (0.63) and to a lesser extent with HDL-cholesterol (0.45), but not with any other plasma lipid or lipoprotein parameters. However, the presence of a factor interfering in the assay was subsequently suspected when significant levels of CETP were measured in normal plasma immunodepleted of CETP as well as in hyperalphalipoproteinemic plasma (19) in which we could not detect CETP by immunoblotting techniques (not illustrated) and in which neutral lipid transfer activity could not be demonstrated.

\section{Interference of apo $A-I$ in the Tween-based CETP immunoassay}

The above observations suggested some heterogeneity of the CETP antigen. We first postulated a difference in conformation of CETP when it is in solution, as in the RIA, and when it is in solid phase, as in immunoblots. However, a second interpretation was that the interference was due to another plasma protein. Considering the unexpected correlation found between CETP and apo A-I (8) we postulated that the interfering factor might be apo A-I itself, and to make the assay more specific we tested a number of different detergents to be used in a pretreatment of the competing antigen and during the competitive immunoreaction. While some improvement was noted with SDS at concentrations of 0.1 and $0.2 \%$, the best results were obtained with Triton when used at concentrations of $1 \%$ during the preincubation of the competing antigen and $0.5 \%$ during the competitive immunoreaction. This is demonstrated in an experiment where a native plasma and a corresponding CETP-depleted plasma, prepared by double passage over an immunoadsorber (TP-2-Sepharose) and shown to be CETP negative by immunoblot, were compared in RIA carried out with either Tween or Triton (Fig. 1). In the Tween assay the CETP-depleted plasma still displayed $42 \%$ of CETP immunoreactivity in the initial plasma, whereas in the Triton assay the same fraction had only $4 \%$ of the initial CETP concentration.

To verify that this observed improvement in the specificity of the assay with Triton was indeed due to an initial interference by apo A-I or apo A-I-containing lipoproteins, the following experiment was carried out. Plastic wells were coated with the CETP normally used as solid-phase antigen (CM-cellulose purified CETP), saturated with BSA, and incubated in the presence of Tween or Triton with dilutions of either plasma or BSA. The wells including controls lacking CETP were then incubated with antibodies against different apolipoproteins, or with TP- 2 in the presence of the appropriate detergent, and the bound antibody quantified. Upon incubation of plasma in the presence of Tween, a high level of apo A-I bound to the immobilized CETP (i.e., 7,000-15,000 cpm of ${ }^{125} \mathrm{I}$-anti-apo A-I IgG over background) but was eliminated in the presence of Triton. In contrast, there is no binding of apo A-II with either detergents, a result that corroborates previous observations on the association of CETP with apo A-I but not with apo A-II (20). In the same experiments we verified that labeled TP-2 binding to the wells coated with CETP was decreased $(30 \%)$ when these wells were preincubated with plasma 


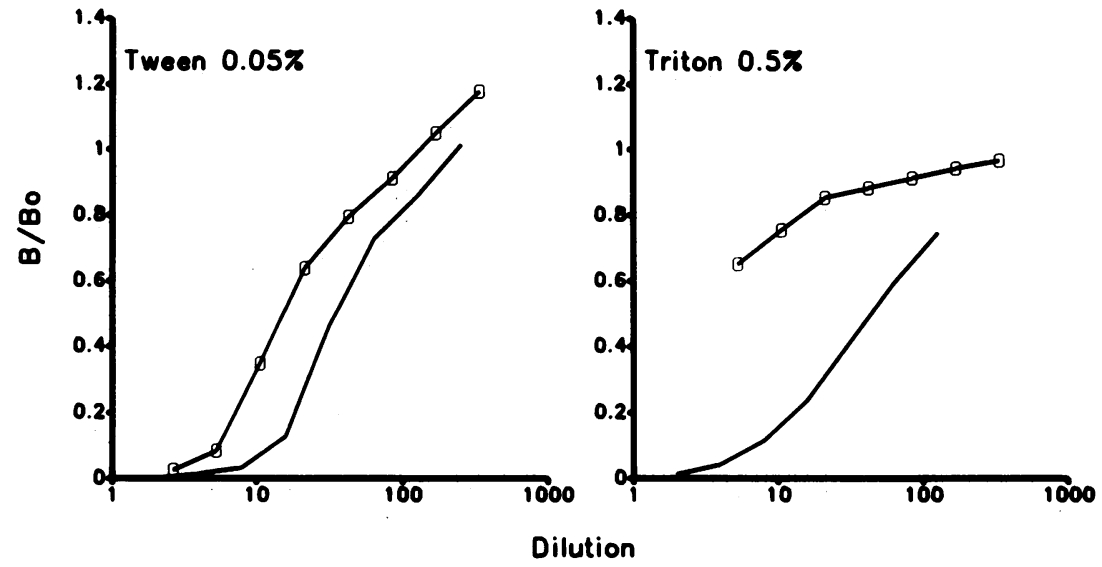

Figure 1. Effects of detergents on the competitive displacement of MAb TP-2 by plasma (solid line) or plasma immunodepleted of CETP by double passage on TP-2-Sepharose (open symbols). The dilutions were calculated based on the starting plasma. or HDL in the presence of Tween and washed, thus supporting the notion of an interference by apo A-I lipoproteins.

\section{Validation and standardization of the} Triton-based assay for CETP

The antigen present in serum was found to be stable for several days at $4^{\circ} \mathrm{C}$ and comparison of several sera stored at 4 and $-80^{\circ} \mathrm{C}$ up to $18 \mathrm{~d}$ indicated that sera stored at $4^{\circ} \mathrm{C}$ were less immunoreactive than frozen samples after $14 \mathrm{~d}$. Therefore, in all studies reported here CETP levels were measured within a week of obtaining blood samples or the sera were stored frozen.

Normolipemic plasma samples were pretreated with various detergents and chaotropic agents or conditions to evaluate if more immunoreactive epitopes could be obtained. Treatment with urea $(2,4$, or $8 \mathrm{M})$ or guanidine $\mathrm{HCl}(4 \mathrm{M})$ for 60 min at $37^{\circ} \mathrm{C}$ decreased the expression of CETP epitope, as did treatment with either $0.1 \%$ EDTA or $0.5 \mathrm{M}$ divalent ions, but repeated (three times) freezing and thawing had no effect. Therefore, none of these disruptive conditions significantly increased the immunoreactivity of serum with MAb TP-2, indicating that all CETP molecules of plasma express the epitope for TP-2 under these conditions of assay.

A pool of normolipemic sera was prepared to serve as a secondary standard for the RIA and calibrated with several preparations of pure CETP. At each stage of CETP purification the affinity of TP-2 for the antigen was comparable (Fig. 2) and parallel displacement curves were obtained indicating

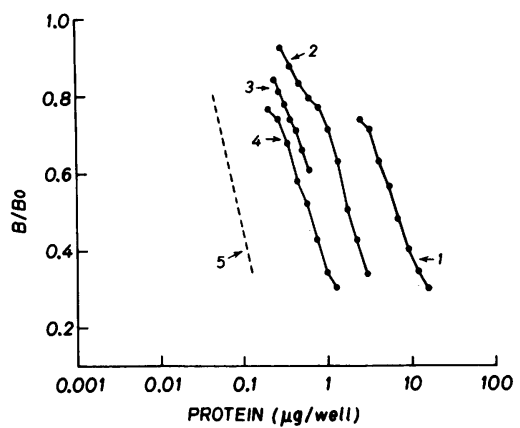

Figure 2. Competitive displacement of MAb TP- 2 by serial dilutions of different fractions from CETP purification. Plasma $(1.21 \mathrm{~g} / \mathrm{ml}$ infranate) ( 1 , phenylSepharose chromatography (2), CM-cellulose chromatography (3), or triglyceride emulsionbound CETP (4) were added to the wells. A

competition curve obtained with a representative serum is plotted (dotted line) based on an arbitrary value and the serial dilutions used to demonstrate its parallelism with the curves obtained with the different purified fractions. that the different steps of the purification procedure did not modify CETP conformation in the vicinity of the TP-2 epitope. Under these conditions two preparations of pure CETP (CETP bound to the lipid emulsion, then delipidated and pretreated with Triton) were assayed by RIA and their protein concentration was measured by amino acid analysis. This yielded values of 2.11 and $2.38 \mu \mathrm{g} / \mathrm{ml}$ for the standard serum pool, which was ascribed a CETP concentration of $2.24 \mu \mathrm{g} / \mathrm{ml}$.

\section{Distribution of CETP in normal plasma}

The density distribution of CETP was first evaluated by Triton-based RIA in fractions obtained by gradient ultracentrifugation of plasma from fasting normolipemic subjects and compared with the concentration of apo A-I (Fig. 3). Under these conditions there was no detectable CETP in fractions of $d>1.06 \mathrm{~g} / \mathrm{ml}$, and two discrete peaks of CETP were observed that were clearly different from those of apo A-I. The two main

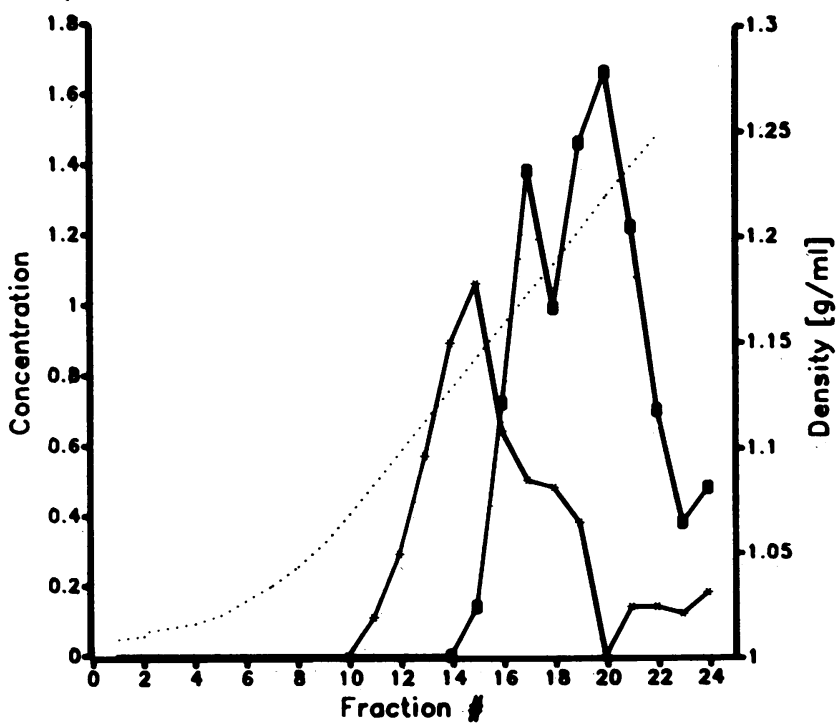

Figure 3. Distribution of CETP and apo A-I as a function of density after gradient ultracentrifugation of a fasting normolipemic plasma sample. Apo A-I (*) and CETP (®) concentrations are given in milligrams/milliliter and in micrograms/milliliter, respectively, using the same scale on the $y$ axis. The density of the fractions is given by the dotted line. 
fractions of CETP coincided with $\mathrm{HDL}_{3}$ and VHDL as seen below with the pooled density subclasses. It should also be noted that with this brief centrifugation all CETP is associated with lipids and nearly all floats at $d<1.25 \mathrm{~g} / \mathrm{ml}$. Competitive RIA between the pooled lipoprotein fractions and the immobilized partially purified CETP gave parallel displacement curves with serum, $\mathrm{HDL}_{2}, \mathrm{HDL}_{3}$, and VHDL (Fig. 4), indicating similar affinity of the antibody for CETP present in the different density fractions. Under these conditions of assay, the concentration of CETP was always highest in either of $\mathrm{HDL}_{3}$ or VHDL, and that in $\mathrm{HDL}_{2}$ varied between subjects, ranging from 1 to $10 \%$ of the total CETP concentration in five fasting normolipemic subjects.

The distribution of CETP was also studied in plasma from several fasting normal donors analyzed by agarose gel electrophoresis and by polyacrylamide gradient gel electrophoresis (Fig. 5, $A$ and $B$ ). In freshly collected plasma CETP comigrated with the slow migrating $\alpha_{2}$ apo A-I-containing lipoproteins (Fig. $5 \mathrm{~A}$ ), an electrophoretic migration that is distinctly faster than that of VLDL or pre- $\beta$-lipoproteins (not illustrated). A certain microheterogeneity of this $\alpha_{2}$-migrating CETP between donors is visible upon close examination (Fig. $5 \mathrm{~A}$ ): the CETP band of donors 1 and 2 has a slower migration, while that of donor 4 is faster and those of donors 3 and 5 show both slow and fast $\alpha_{2}$-subfractions. The same five plasmas analyzed by nondenaturing gradient gel electrophoresis also exhibited heterogeneity in the size distribution of CETP, which is present in three distinct bands with apparent $M_{\mathrm{r}}$ of 129,133 , and $154 \mathrm{kD}$ (Fig. $5 \mathrm{~B}$ ). The concentration of these bands varies between donors but there is no evidence that this size heterogeneity corresponds to the charge heterogeneity noted in Fig. $5 \mathrm{~A}$. When plasma samples were kept at $4^{\circ} \mathrm{C}$ for a few days and electrophoresed on gradient gel, a band of a smaller size (108 $\mathrm{kD}$ ) appeared that corresponded to the size of the CM-cellulose purified CETP fraction (Fig. 6). Given its small size, this fraction that was shown by RIA to contain apo A-I and apo D cannot accommodate both apolipoproteins in the same particle and is probably heterogeneous.

\section{Effect of a fat meal on plasma CETP levels}

After a fat meal containing $80 \mathrm{~g}$ of fat in the form of $35 \%$ dairy cream, plasma cholesterol levels remained constant in the five subjects studied, while triglycerides increased after 2 or 2.5 and
$5 \mathrm{~h}$ and returned toward baseline at $7 \mathrm{~h}$. During this period, and compared with a basal value of $100 \%$ at $0 \mathrm{~h}$, CETP levels increased only slightly in the five subjects after the fat meal, reaching levels of $111 \pm 12,112 \pm 13$, and $109 \pm 13 \%$ at $2-2.5,5$, and $7.5 \mathrm{~h}$, respectively. This small increase in CETP mass after the meal explains only part of the increase in CETP activity noted earlier by some of us (21). In the subsequent studies all normolipemic blood samples were obtained after an overnight fast.

\section{Variation of CETP plasma levels in normolipemic subjects, and relationship with lipid \\ and apolipoprotein levels}

Study sample I. 50 normal volunteers were studied. This population consisted of 24 male and 26 female subjects ranging in age from 24 to 57 yr. Plasma lipoprotein, apo A-I, and CETP concentrations for this population are described in Table I. All subjects had values for total cholesterol and triglyceride that were less than the 90th percentile after adjustment for age and sex using the Lipid Research Clinics population data for North America. HDL-cholesterol concentrations ranged between 0.9 and $2.7 \mathrm{mM} /$ liter. CETP levels varied nearly fourfold (1.04$3.55 \mu \mathrm{g} / \mathrm{ml}$ ) and were slightly higher in female as compared with male subjects $(1.92 \pm 0.52$ vs. $1.50 \pm 0.26 \mu \mathrm{g} / \mathrm{ml})$.

Pearson correlation coefficients were calculated using the SAS statistical program (18). The correlation matrix is illustrated in Table II. Using CETP as the dependent variable, significant correlations were found with apo A-I $(r=0.38)$ and HDL-triglyceride $(r=0.31)$. Plasma triglyceride concentration was positively associated with HDL-triglyceride and negatively associated with the HDL-cholesterol to apo A-I ratio. No relationship was found between CETP and plasma triglyceride or between CETP and the HDL-cholesterol/HDL triglyceride ratio, or between CETP and the apo A-I/HDL-cholesterol ratio. Stepwise multiple regression analyses were carried out using CETP as the dependent variable. A-I and HDL-triglyceride accounted for $24 \%$ of the observed variability in CETP levels. No improvement in the model was obtained by addition of other variables.

Study sample II. A second population of 29 normal volunteers was studied at a later date to determine whether any significant relationships were also demonstrable between CETP and other apolipoprotein concentrations. Lipid, apoli-
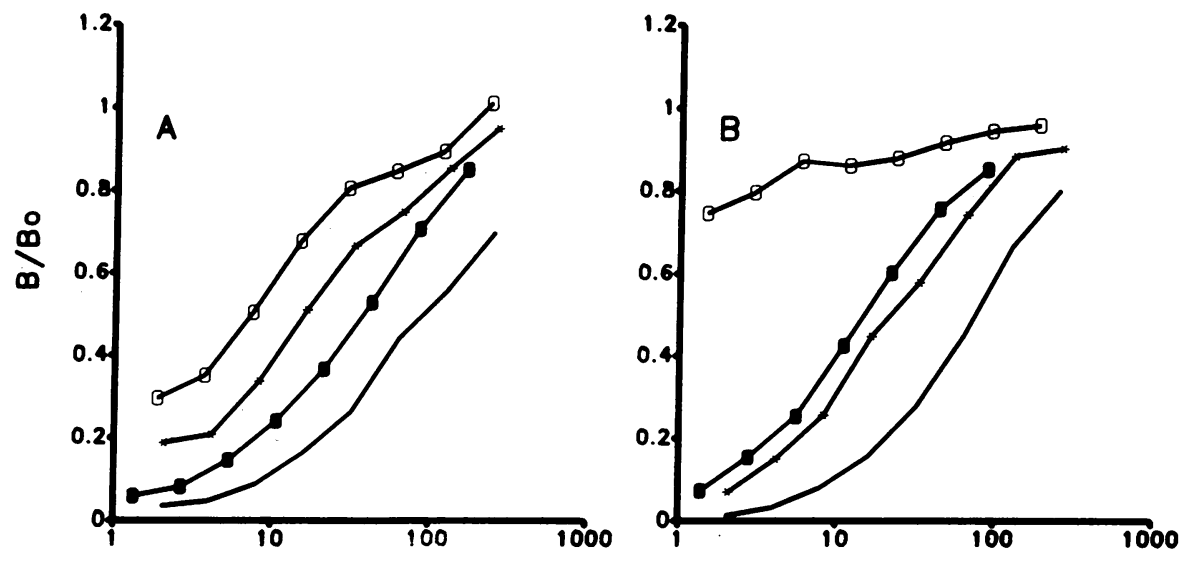

Dilution
Figure 4. Competitive displacement curves of MAb TP-2 by pooled lipoprotein subfractions isolated by gradient ultracentrifugation of two representative fasting normolipemic plasma $(A$ and $B)$. - , Starting plasma; $\longrightarrow-, \mathrm{HDL}_{2} ;-\bullet-, \mathrm{HDL}_{3}$; $-*-$, VHDL. The dilutions refer to the dilution of each fraction relative to the starting plasma. 

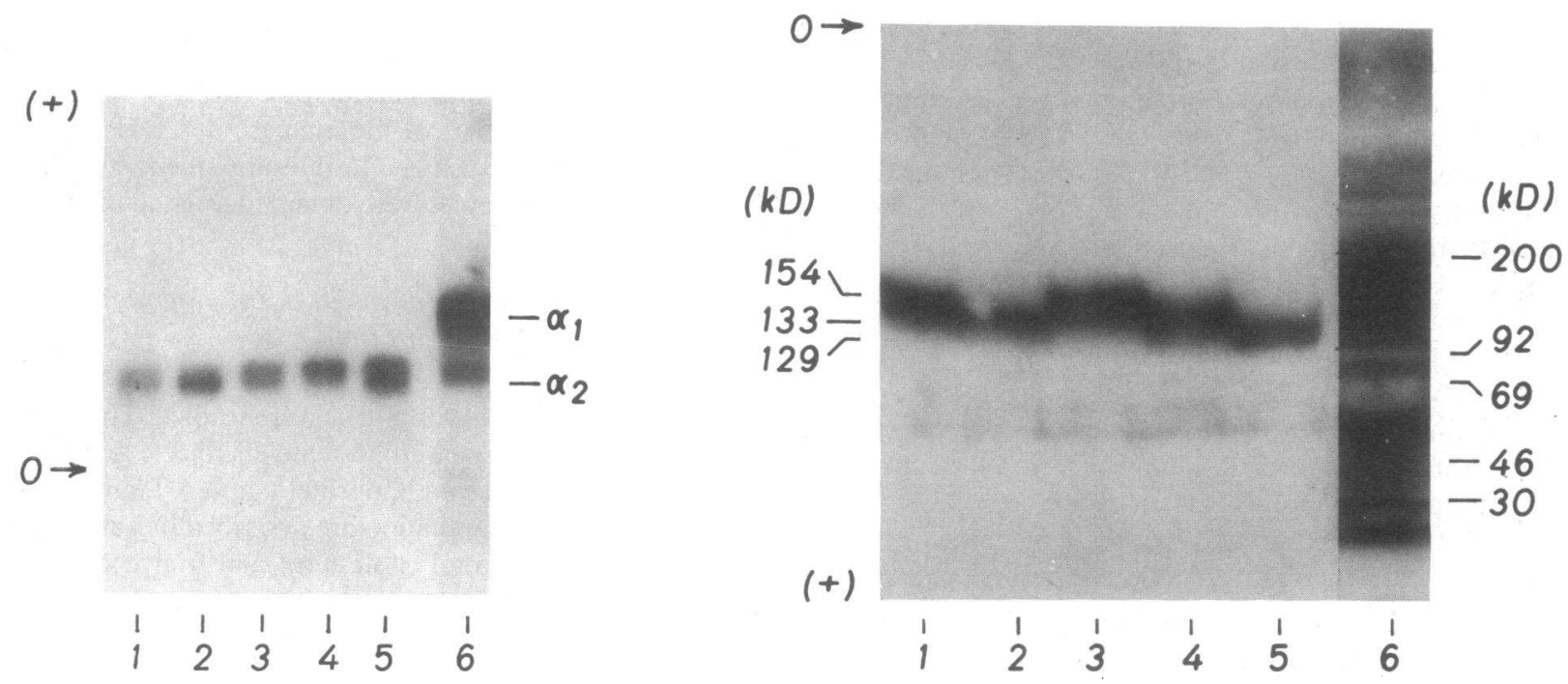

Figure 5. A, Immunoblots of normal plasma electrophoresed on agarose gel. Lanes 1-5 represent the immunoblots with MAb TP-2 of plasma from five different donors analyzed on the same day. Lane 6 represents the immunoblot with anti-apo A-I for one representative plasma. $B$, Immunoblots of normal plasma electrophoresed on nondenaturing gradient gel. The identification of the lanes is the same as for $\boldsymbol{A}$.

poprotein, and CETP levels for this population of 21 male and 8 female subjects are described in Table III. Cholesterol and triglyceride levels were below the 90th percentile adjusted for age and sex. CETP levels were slightly lower than those obtained for study sample I, reflecting the proportionately greater number of male subjects in the second sample as well as other more subtle differences, such as age and HDL-cholesterol to apo A-I ratio. CETP levels ranged from 0.53 to $2.35 \mu \mathrm{g} / \mathrm{ml}$, and the means for male and female subjects were $1.12 \pm 0.44$ and $1.47 \pm 0.43$, respectively.

Pearson correlation coefficients were calculated as described above. Using CETP as the dependent variable, again significant correlations were found with apo A-I $(r=0.41)$ as well as HDL-cholesterol $(r=0.41)$, but HDL-triglycerides were not measured in this group. A new observation was noted with the apparition of a positive correlation between CETP and apo E levels $(r=0.43)$, which had not been observed in the same group with the previous Tween-based assay for CETP (8). There were, however, no significant relationships between

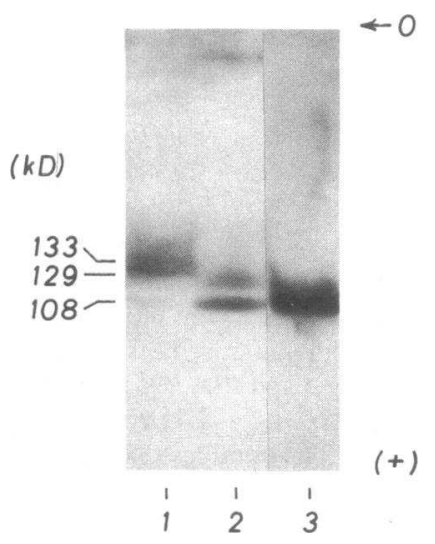

Figure 6. Effect of storage on the size heterogeneity of plasma CETP electrophoresed on polyacrylamide gradient gel. Lane 1, plasma from a normolipemic donor analyzed on the same day; lane 2 , plasma from the same donor stored 1 wk at $4^{\circ} \mathrm{C}$; lane 3 , purified CETP obtained after CM-cellulose chromatography.
CETP and the level of any of apo A-II, D, or B. Nor was CETP correlated in a significant degree with either apo A-I/apo A-II ratios or HDL-cholesterol/apo A-I ratios (Table IV). Stepwise multiple regression showed that $35 \%$ of the variability in CETP could be accounted for by apo A-I (partial $r^{2}=17 \%$ ) and apo $\mathrm{E}$ (partial $r^{2}=18 \%$ ). No improvement in the fit of the model was provided by the addition of HDL-cholesterol.

\section{Discussion}

The antibody used in this study was obtained from mice immunized with highly purified CETP bound to a triglyceride microemulsion (2). Several lines of evidence demonstrate the specificity of the MAb TP-2, including its reactivity with a single protein of $M_{r} 74,000$ in plasma, with the purified CETP (3), and with the fusion protein obtained by expression of

Table I. Study Sample I: Plasma Lipoprotein, Apo A-I, and CETP Concentrations in Normal Volunteers

\begin{tabular}{llcc}
\hline \multicolumn{1}{c}{ Parameter } & \multicolumn{1}{c}{ Unit } & \multicolumn{1}{c}{ Mean \pm SD } & \multicolumn{1}{c}{ Range } \\
\hline Age & $\mathrm{yr}$ & $33.8 \pm 9.4^{*}$ & $24-57$ \\
Total cholesterol & $\mathrm{mM} / \mathrm{liter}$ & $4.81 \pm 0.73$ & $3.39-7.14$ \\
Triglyceride & $\mathrm{mM} /$ liter & $0.91 \pm 0.17$ & $0.36-2.34$ \\
HDL-cholesterol & $\mathrm{mM} /$ liter & $1.54 \pm 0.13$ & $0.96-2.74$ \\
HDL-triglyceride & $\mathrm{mM} / \mathrm{liter}$ & $0.150 \pm 0.003$ & $0.05-0.29$ \\
Apo A-I & $\mathrm{mg} / \mathrm{ml}$ & $1.35 \pm 0.10$ & $0.69-1.98$ \\
HDL-cholesterol/ & & & \\
$\quad$ Apo A-I & $\mathrm{mM} / \mathrm{liter}: \mathrm{mg} / \mathrm{ml}$ & $1.17 \pm 0.06$ & $0.56-1.75$ \\
CETP & $\mu \mathrm{g} / \mathrm{ml}$ & $1.73 \pm 0.25$ & $1.04-3.55$ \\
& & & \\
\hline
\end{tabular}

$* n=50$ (24 male, 26 female).

‡ CETP levels are measured by RIA in the presence of Triton. 
Table II. Study Sample I: Pearson Correlation Coefficients for Variables Determined in 50 Normolipemic Subjects

\begin{tabular}{|c|c|c|c|c|c|c|c|c|}
\hline & CETP & Age & Total cholesterol & Triglyceride & HDL-cholesterol & HDL-triglyceride & Apo A-I & HDL-cholesterol/Apo A-I \\
\hline CETP & 1.0 & & & & & & & \\
\hline Age & 0.22 & 1.0 & & & & & & \\
\hline Total cholesterol & 0.11 & $0.61^{*}$ & 1.0 & & & & & \\
\hline Triglyceride & -0.05 & $0.36^{*}$ & $0.45^{*}$ & 1.0 & & & & \\
\hline HDL-cholesterol & 0.23 & 0.05 & 0.16 & -0.29 & 1.0 & & & \\
\hline HDL-triglyceride & $0.31^{*}$ & 0.15 & 0.17 & $0.44^{*}$ & $0.35^{*}$ & 1.0 & & \\
\hline Apo A-I & $0.38^{*}$ & -0.01 & 0.24 & 0.12 & $0.56^{*}$ & $0.38^{*}$ & 1.0 & \\
\hline HDL-cholesterol/Apo A-I & -0.16 & -0.02 & -0.19 & $-0.45^{*}$ & $0.40^{*}$ & -0.06 & $-0.51^{*}$ & 1.0 \\
\hline
\end{tabular}

${ }^{*} P<0.05$.

the cDNA coding for CETP (22) in a bacterial system (23). The specificity of TP-2 is further demonstrated by its capacity to inhibit or remove all neutral lipid transfer activity in plasma (3).

We have shown here that in the presence of a low concentration of Tween $(0.05 \%)$ there is a significant binding of apo A-I but not of apo A-II to the immobilized CETP. These observations are in accord with the results of others showing an association of CETP with lipoproteins containing apo A-I, but not with those containing apo A-II (20). With a high concentration of Triton (1\%), the binding of apo A-I to the immobilized CETP becomes undetectable and concurrently CETPdepleted plasma does not compete anymore in the CETP assay. No other interference is apparent as demonstrated by the lack of effect of other dissociating or chaotropic agents. In other work we have shown that the treatment of plasma or HDL by Tween $(0.05 \%)$ causes the dissociation of apo A-Icontaining lipoproteins and the appearance of free apo A-I and HDL-lipid ghosts (Marcel, Y. L., X. Collet, and E. Raffai, unpublished observations). Considering the effect of Tween, we cannot conclude that the decreased TP- 2 binding in the presence of $\mathrm{HDL}$ or plasma is the result of a competition by apo A-I alone since it could also be caused by the HDL-lipid ghosts. In the presence of Triton, CETP present in VHDL, $\mathrm{HDL}_{3}$, and $\mathrm{HDL}_{2}$ has a similar affinity for TP-2 (Fig. 4), al-

Table III. Study Sample II. Lipoprotein, Apolipoprotein, and CETP Concentrations in Plasma Samples from Fasting Normolipemic Volunteers

\begin{tabular}{llcc}
\hline \multicolumn{1}{c}{ Parameter } & \multicolumn{1}{c}{ Unit } & Mean \pm SD & Range \\
\hline Age & $\mathrm{yr}$ & $39.1 \pm 13.1^{*}$ & $25-74$ \\
Total cholesterol & $\mathrm{mM} / \mathrm{liter}$ & $4.76 \pm 0.64$ & $3.36-6.05$ \\
LDL-cholesterol & $\mathrm{mM} / \mathrm{liter}$ & $2.83 \pm 0.66$ & $1.42-4.09$ \\
HDL-cholesterol & $\mathrm{mM} / \mathrm{liter}$ & $1.48 \pm 0.34$ & $0.85-2.14$ \\
Apo A-I & $\mathrm{mg} / \mathrm{ml}$ & $1.37 \pm 0.30$ & $0.92-2.27$ \\
Apo A-II & $\mathrm{mg} / \mathrm{ml}$ & $0.30 \pm 0.08$ & $0.18-0.47$ \\
Apo B & $\mathrm{mg} / \mathrm{ml}$ & $75.5 \pm 19.3$ & $31.5-106.0$ \\
Apo D & $\mu \mathrm{g} / \mathrm{ml}$ & $227.8 \pm 49.4$ & $116.8-343.9$ \\
Apo E & $\mu \mathrm{g} / \mathrm{ml}$ & $64.5 \pm 20.8$ & $23.0-107.1$ \\
CETP & $\mu \mathrm{g} / \mathrm{ml}$ & $1.21 \pm 0.47$ & $0.53-2.35$
\end{tabular}

$* n=29$ (21 male, 8 female). lowing the application of this immunoassay to the study of CETP distribution and concentration in plasma.

In the plasma of normal fasting subjects CETP was most concentrated in $\mathrm{HDL}_{3}$ and VHDL and very low amounts were found in the protein fraction $(d>1.25 \mathrm{~g} / \mathrm{ml})$, in general agreement with earlier reports based on determination of CETP activity $(20,21,24)$. In the five normal subjects analyzed, the greatest relative variation in CETP concentration (1-10\% of total) was seen in the $\mathrm{HDL}_{2}$. While this variation could have some physiological significance, it is more probably related to the incomplete separation and/or collection of $\mathrm{HDL}_{2}$ and $\mathrm{HDL}_{3}$. On the other hand, it is significant that under the condition of minimum sheer force afforded by single spin gradient ultracentrifugation, we observed no association of CETP with either VLDL or LDL in fasting normal subjects (Fig. 3). The absence of CETP signal in the region of LDL size upon gradient gel electrophoresis (Fig. $5 \mathrm{~B}$ ) supports the validity of the above observations. Furthermore, these experiments also demonstrated that CETP is present in small and dense particles of limited and discrete size heterogeneity $(129,133$, and $154 \mathrm{kD})$, which are smaller than the bulk of apo A-I-containing lipoproteins. Likewise, we have shown that the electrophoretic migration of plasma CETP is slower than that of the bulk of apo A-I lipoproteins. The major apo A-I-containing fraction has an $\alpha$-migration, while the minor apo A-I fraction migrates more slowly and as such has been initially designated pre- $\beta$ apo A-I lipoprotein by others (25). We have chosen here to designate the major fraction as $\alpha_{1}$-lipoproteins and the minor as $\alpha_{2}$-lipoproteins based on the historical development of lipoprotein nomenclature (26). Accordingly, we have demonstrated here that all CETP-containing lipoproteins present in plasma have an $\alpha_{2}$-migration (Fig. $5 \mathrm{~A}$ ), in clear contradiction with the recent results of others who found most of CETP in $\alpha_{1}$-migration with only $28 \%$ in $\alpha_{2}$ (or pre- $\beta$ ) and the rest in $\beta$ (27).

Our results on the size distribution of plasma CETP are also at odds with the same report (27), which indicated the occurrence of CETP signals in particles with a size range as wide as that of the apo A-I. Although these authors did not present any additive or serial immunoblots of the same electrophoretogram for a conclusive demonstration of the coincidence of the antigenic signals, they concluded that nearly a third of plasma CETP comigrated with a fraction also containing apo A-I, apo D, and LCAT, identified as Lp A-I pre- $\beta_{3}$ and of a size larger than the major apo A-I lipoproteins. The 


\begin{tabular}{|c|c|c|c|c|c|c|c|c|c|c|c|c|}
\hline & \multirow[b]{2}{*}{ CETP } & \multirow[b]{2}{*}{ Age } & \multirow[b]{2}{*}{$\begin{array}{c}\text { Total } \\
\text { cholesterol }\end{array}$} & \multirow[b]{2}{*}{ Triglyceride } & \multirow[b]{2}{*}{$\begin{array}{c}\text { LDL } \\
\text { cholesterol }\end{array}$} & \multirow[b]{2}{*}{$\begin{array}{c}\text { HDL- } \\
\text { cholesterol }\end{array}$} & \multicolumn{5}{|c|}{ Apo } & \multirow[b]{2}{*}{$\begin{array}{l}\text { HDL-cholesterol, } \\
\text { Apo A-I }\end{array}$} \\
\hline & & & & & & & A-I & A-II & B & D & $\mathbf{E}$ & \\
\hline CETP & 1.0 & & & & & & & & & & & \\
\hline Age & 0.24 & 1.0 & & & & & & & & & & \\
\hline Total cholesterol & 0.28 & 0.09 & 1.0 & & & & & & & & & \\
\hline Triglyceride & -0.15 & 0.22 & $0.54^{*}$ & 1.0 & & & & & & & & \\
\hline LDL-cholesterol & 0.09 & 0.11 & $0.83^{*}$ & $0.53^{*}$ & 1.0 & & & & & & & \\
\hline HDL-cholesterol & $0.41^{*}$ & -0.06 & 0.00 & $-0.49^{*}$ & $-0.43^{*}$ & 1.0 & & & & & & \\
\hline Apo A-I & $0.41^{*}$ & 0.00 & 0.09 & -0.26 & -0.32 & $0.75^{*}$ & 1.0 & & & & & \\
\hline Apo A-II & 0.03 & 0.26 & 0.23 & 0.13 & 0.24 & 0.04 & -0.10 & 1.0 & & & & \\
\hline Apo B & 0.06 & -0.04 & 0.80 & $0.70^{*}$ & $0.88^{*}$ & -0.38 & -0.08 & 0.16 & 1.0 & & & \\
\hline Apo D & 0.34 & 0.19 & 0.25 & -0.22 & 0.22 & 0.27 & -0.01 & 0.12 & -0.04 & 1.0 & & \\
\hline Apo E & $0.43^{*}$ & 0.03 & $0.51^{*}$ & 0.22 & $0.42^{*}$ & -0.07 & 0.01 & -0.28 & $0.46^{*}$ & 0.20 & 1.0 & \\
\hline HDL-cholesterol/Apo A-I & 0.05 & -0.10 & -0.11 & -0.38 & 0.20 & $-0.44^{*}$ & -0.25 & 0.20 & -0.40 & $-0.41^{*}$ & -0.10 & 1.0 \\
\hline
\end{tabular}

$* P<0.05$.

minimum $M_{r}$ of such a complex containing one molecule of each of the above and including $10 \%$ of lipids to account for its flotation in the VHDL would be $\sim 220 \mathrm{kD}$, which is significantly greater than the largest size of the CETP signal observed here. Our results, therefore, argue against the existence of such a complex. In effect, immunoblots with anti-LCAT of fresh plasma electrophoresed on agarose gel demonstrate that LCAT is most often found in $\alpha_{1}$-fractions with minor signals in $\alpha_{2}$ and $\beta$-fractions (Zawadzki, Z., R. W. Milne, A. R. Tall, and Y. L. Marcel, unpublished observations). It is likely that the discrepancy in the results of others is related to the specificity of the antibodies and of the detection system that was used.

The two groups of normal subjects studied consisted of volunteers, mostly Caucasian, selected on the basis of fasting normal lipid levels, good health, and absence of lipid modifying medication. In the two groups plasma levels of CETP varied over a wide range (3.4- and 4.4-fold), with a distribution similar to that observed in the same groups for triglyceride, HDL-cholesterol, apo A-I, A-II, D, and E (Tables I and III).

It is noteworthy that the correlation between CETP and apo A-I, which was first noted with the Tween-based RIA (8), does decrease when CETP levels are measured with the Triton-based assay in the same plasma of normal subjects, but remains significant ( $r=0.53$ and 0.38 , respectively). This observation together with the demonstration of apo A-I binding to solid-phase CETP indicates a partial competition in the binding of MAb TP-2 and apo A-I to CETP at low concentrations of Tween. Therefore, under these assay conditions the domain which CETP binds apo A-I-containing lipoproteins in their Tween-dissociated form is close to or overlapping with the TP-2 epitope that has been recently assigned to a hydrophobic 26 amino acid sequence on the $\mathrm{COOH}$ terminus of the molecule (28). The significant correlation that is still observed between CETP and apo A-I in the absence of any demonstrable interference suggests that the concentration of circulating CETP is a function of apo A-I availability for CETP binding in agreement with their documented affinity for each other.

On the other hand, the lack of correlation between CETP and apo A-II indicates that CETP has little affinity for binding to apo A-II-containing lipoproteins. This is in agreement with Cheung et al., who observed that only $7 \%$ of plasma CETP activity was present in lipoproteins containing both apo A-I and A-II, the remainder being associated with lipoproteins containing apo A-I but no A-II (20). Likewise, the lack of correlation between CETP and apo D corroborates previous observations that these two proteins are not associated in plasma and represent distinct entities (29).

The correlation between CETP and HDL-triglyceride (Table II) reflects the expected relationship between CETP mass and activity. This relationship is probably dependent in part on the availability of triglyceride-rich particles for cholesteryl ester exchange and, indeed, increasing plasma triglyceride concentrations were associated with triglyceride enrichment and cholesterol depletion of HDL. There was not, however, a negative association between CETP mass and HDL-cholesterol concentration. Obviously, other parameters such as the net flux and the clearance rate of intestinal and hepatic triglyceride-rich lipoproteins need to be considered together with CETP levels as the limiting factors for plasma HDL-cholesterol in normolipemic subjects. Indeed, hypertriglyceridemia, particularly in type IV patients, is associated with low HDLcholesterol and this correlation extends into the normal population (30). However it remains to be established whether the inverse correlation that has been repeatedly observed between plasma triglyceride and HDL-cholesterol concentrations is present because at a given CETP concentration cholesterol ester transfer is dependent on the clearance rate of triglyceride-rich lipoprotein (i.e., allowing more time for transfer), on net flux of triglyceride-rich lipoproteins (i.e., more particles allowing more transfer to each), or both.

Finally, our observation on the positive correlation between CETP and apo E levels (Table IV) is most unexpected and deserves further study. No specific association between CETP and apo E-containing lipoproteins has been reported and the kinetics of transfer of apo $E$ and cholesteryl esters between HDL and chylomicrons have been shown to be independent of one another (31). However, cholesteryl ester transfer activity is increased in dysbetalipoproteinemia (32), but the mechanism for this increase and its relationship to apo $E$ levels is unknown.

In conclusion, the present studies show that CETP levels are positively correlated with both apo A-I and apo E levels. 
While the correlation of CETP and apo A-I appears to directly reflect the association of CETP with specific apo A-I-containing lipoproteins, the correlation between CETP and apo $E$ is difficult to interpret, but suggests the hypothesis that the CETP-mediated pathway favors the return of cholesteryl esters to the liver via apo E-containing lipoproteins. In addition, we have shown that plasma CETP, which is mostly associated with $\mathrm{HDL}_{3}$ and VHDL, displays an $\alpha_{2}$ electrophoretic migration and is present in discrete particles with $M_{\mathrm{r}}$ ranging from 129 to $154 \mathrm{kD}$.

\section{Acknowledgments}

This work was supported by grants from the Medical Research Counci of Canada (PG-27), the Quebec Heart Foundation, and the National Institutes of Health (HL-22682 and HL-21006). Ross W. Milne is a Scientist of the Medical Research Council of Canada.

\section{References}

1. Tall, A. R. 1986. Plasma lipid transfer proteins. J. Lipid Res. 27:361-367.

2. Hesler, C. B., T. L. Swenson, and A. R. Tall. 1987. Purification and characterization of a human plasma cholesteryl ester transfer protein. J. Biol. Chem. 262:2275-2282.

3. Hesler, C. B., A. R. Tall, T. L. Swenson, P. K. Weech, Y. L. Marcel, and R. W. Milne. 1988. Monoclonal antibodies to the $M_{r}$ 74,000 cholesteryl ester transfer protein neutralize all of the cholesteryl ester and triglyceride transfer activities in human plasma. J. Biol. Chem. 263:5020-5023.

4. Tall, A. R., E. Abreu, and J. Shuman. 1983. Separation of a plasma phospholipid exchange protein. J. Biol. Chem. 258:21742180.

5. Marcel, Y. L., C. Vézina, B. Teng, and A. Sniderman. 1980. Transfer of cholesterol esters between human high density lipoproteins and triglyceride-rich lipoproteins controlled by a plasma protein factor. Atherosclerosis. 35:127-133.

6. Mahley, R. W., D. Y. Hui, T. L. Innerarity, and K. H. Weisgraber. 1981. Two independent lipoprotein receptors on hepatic membranes of dog, swine and man. Apo-B,E and apo-E receptors. $J$. Clin. Invest. 68:1197-1206.

7. Yamada, N., D. Shames, J. B. Stoudemire, and R. J. Havel. 1986. Metabolism of lipoprotein B-100 in blood plasma of rabbits: heterogeneity related to the presence of apolipoprotein E. Proc. Natl. Acad. Sci. USA. 83:3479-3483

8. Marcel, Y. L., H. Czarnecka, R. McPherson, C. Hesler, R. W. Milne, and A. R. Tall. 1988. Arteriosclerosis. 8:593a. (Abstr.)

9. Havel, R. J., H. A. Eder, and J. H. Bragdon. 1958. The distribution and chemical composition of ultracentrifugally separated lipoproteins in human serum. J. Clin Invest. 34:1345-1353.

10. Terpstra, A. H. M., C. J. H. Woodward, and F. Sanchez-Muniz. 1981. Improved techniques for the separation of serum lipoproteins by density gradient ultracentrifugation. Anal. Biochem. 111:149-157.

11. Milne, R. W., R. Theolis, R. B. Verdery, and Y. L. Marcel. 1983. Characterization of monoclonal antibodies against human low density lipoprotein. Arteriosclerosis. 3:23-30.

12. Marcel, Y. L., M. Hogue, R. Theolis, and R. W. Milne, 1982. Mapping of antigenic determinants of human apolipoprotein B using monoclonal antibodies against low density lipoproteins. J. Biol. Chem. 257:13165-13168.

13. Vezina, C. A., R. W. Milne, P. K. Weech, and Y. L. Marcel. 1988. Apolipoprotein distribution in human lipoproteins separated by polyacrylamide gradient gel electrophoresis. J. Lipid Res. 29:573-585.
14. 1974. Lipid Research Clinics Program. Manual of laboratory operations. U. S. Government printing office, Bethesda, MD. 1-81.

15. Marcel, Y. L., D. Jewer, C. Vézina, P. Milthorp, and P. K. Weech. 1987. Expression of human apolipoprotein A-I epitopes in high density lipoproteins and in serum. J. Lipid Res. 28:768-777.

16. Weech, P. K., R. Camato, R. W. Milne, and Y. L. Marcel. 1986. Apolipoprotein $\mathrm{D}$ and cross-reacting human plasma apolipoprotein identified using monoclonal antibodies. J. Biol. Chem. 261:7941-7951.

17. Milne, R. W., P. Douste-Blazy, L. Retegui, and Y. L. Marcel. 1981. Characterization of monoclonal antibodies against human apolipoprotein E. J. Clin. Invest. 68:111-117.

18. 1985. SASr Language Guide for personal computers. 6th ed. SAS Institute Inc., Cary, NC. 429 pp.

19. Koizumi, J., H. Mabuchi, A. Yoshimura, I. Michishita, M. Takado, H. Itoh, Y. Sakai, T. Sakai, K. Ueda, and R. Takeda. 1985. Deficiency of serum cholesteryl ester transfer activity in patients with familial hyperalphalipoproteinemia. Atherosclerosis. 58:175-186.

20. Cheung, M. C., A. C. Wolf, K. D. Lum, J. H. Tollefson, and J. J. Albers. 1986. Distribution and localization of lecithin: cholesterol acyl-transferase and cholesteryl esters transfer activity in A-I containing lipoproteins. J. Lipid Res. 27:1135-1144.

21. Tall, A., D. Sammett, and E. Granot. 1986. Mechanisms of enhanced cholesteryl ester transfer from high density lipoproteins to apolipoprotein B-containing lipoproteins during alimentary lipemia. J. Clin. Invest. 77:1163-1172.

22. Drayna, D., A. S. Jarnagin, J. McLean, W. Henzel, W. Kohr, C. Fielding, and R. Lawn. 1987. Cloning and sequencing of human cholesteryl ester transfer protein cDNA. Nature (Lond.). 327:632-634.

23. Swenson, T., A. Tall, C. Hesler, M. Brown, E. Quinet, P. Trotta, M. Haslanger, F. Gaeta, Y. Marcel, and R. Milne. 1988. Mechanism of cholesteryl ester transfer protein (CETP) inhibition by neutralizing monoclonal antibodies (Mabs). Arteriosclerosis. 8:593a. (Abstr.)

24. Pattnaik, N. M., and D. B. Zilversmit. 1979. Interaction of cholesteryl ester transfer exchange protein with human plasma lipoproteins and phospholipid vesicles. J. Biol. Chem. 254:2782-2786.

25. Kunitake, S. T., K. J. LaSala, and J. P. Kane. 1985. Apolipoprotein A-containing lipoproteins with pre beta electrophoretic mobility. J. Lipid Res. 26:549-555.

26. Alaupovic, P. 1980. The concepts, classification systems and nomenclatures of human plasma lipoproteins. In CRC Handbook of Electrophoresis. L. A. Lewis and J. J. Oppet, editors. CRC Press, Inc., Boca Raton, FL. 27-46.

27. Francone, O. L. A. Gurakar, and C. Fielding. 1989. Distribution and functions of lecithin:cholesterol acyltransferase and cholesteryl ester transfer protein in plasma lipoproteins. J. Biol. Chem. 264:7066-7072.

28. Swenson, T. L., C. B. Hesler, M. L. Brown, E. Quinet, P. P. Trotta, M. F. Haslanger, F. C. A. Gaeta, Y. L. Marcel, R. W. Milne, and A. R. Tall. 1989. Mechanism of cholesteryl ester transfer protein inhibition by a neutralizing monoclonal antibody and mapping of the monoclonal antibody epitope. J. Biol. Chem. 264:14318-14326.

29. Morton, R. E., and D. B. Zilversmit. 1981. The separation of apo D from cholesteryl ester transfer protein. Biochim. Biophys. Acta. 663:350-355.

30. Phillips, N. R., R. J. Havel, and J. P. Kane. 1982. Serum apolipoprotein A-I levels: relationship to lipoprotein levels and selected demographic variables. Am. J. Epidemiol. 116:302-313.

31. Marcel, Y. L., C. Vezina, and R. W. Milne. 1983. Cholesteryl ester and apolipoprotein $\mathrm{E}$ transfer between human high density lipoproteins and chylomicrons. Biochim. Biophys. Acta. 750:411-417.

32. Tall, A. R., E. Granot, B. Brocia, I. Tabas, C. Hesler, K. Williams, and M. Denke. 1987. Accelerated transfer of cholesteryl esters in dyslipidemic plasma. Role of cholesteryl ester transfer protein. J. Clin. Invest. 79:1217-1225. 